\title{
The role of apoptosis in blepharoptosis
}

E Şahlı', BM Hoşal', G Zilelioğlu' ${ }^{1}$ N Dinçer ${ }^{2}$ and GG Tezel ${ }^{3}$

\begin{abstract}
Purpose The purpose of this study is to evaluate the role of apoptosis in the pathogenesis of blepharoptosis.

Patients and methods Forty-five eyelids of 43 consecutive patients ( 16 female, 27 males) that underwent levator resection surgery for ptosis correction were included in the study. Twenty-six of the eyelids had congenital myogenic ptosis and 19 had aponeurotic ptosis. Levator palpebrae superioris function and height of the vertical palpebral fissure were measured in all patients. After levator resection surgery, the distal part of the levator aponeurosis was fixed and sent for evaluation. Apoptotic cells were detected using Apop Tag Plus Peroxidase In Situ Apoptosis Detection Kit. Results The mean levator palpebrae superioris function was $8.4 \mathrm{~mm}$ (range $5-10 \mathrm{~mm}$ ) in congenital ptosis group and $12.1 \mathrm{~mm}$ (range $10-17 \mathrm{~mm}$ ) in the aponeurotic ptosis group. The mean height of the vertical palpebral fissure in patients with congenital ptosis and aponeurotic ptosis were $6.5 \mathrm{~mm}$ (range $5-9 \mathrm{~mm}$ ) and $6.1 \mathrm{~mm}$ (3-9 mm), respectively. The mean apoptotic index of congenital ptosis and aponeurotic ptosis were 27.3 (16-39) and 29.8 (18-41), respectively. There was no statistically significant difference between congenital and aponeurotic ptosis groups in a mean apoptotic index $(P<0.05)$. Apoptotic index was not correlated with age, levator palpebrae superioris function, palpebral fissure height, and lid crease height in two groups.

Conclusion We found no statistically significant difference between two subtypes of blepharoptosis regarding apoptosis. According to this study, apoptosis seems to have no significant role in the development of aponeurotic blepharoptosis.
\end{abstract}

Eye (2013) 27, 823-827; doi:10.1038/eye.2013.73; published online 19 April 2013

Keywords: blepharoptosis; apoptosis; aponeurotic ptosis

\section{Introduction}

Blepharoptosis indicates the abnormal drooping of the upper lid caused by decreased levator palpebrae superioris function or disinsertion of the aponeurosis with normal levator function. Two classification systems are used to distinguish blepharoptosis. It may be classified as congenital or acquired based on onset of disease. Otherwise, it may be classified by the cause. ${ }^{1}$ The most common type of congenital blepharoptosis results from a margin, and the most common type of acquired blepharoptosis results from an aponeurotic pathology. ${ }^{2}$

Congenital myogenic ptosis results from dysgenesis of the levator muscle. Instead of normal muscle fibers, fibrous or adipose tissue replaces the muscle tissue. ${ }^{3}$ Histological specimens showed loss of cross striations, decrease in muscle fiber diameter, sarcolemmal retraction, nuclei alignment, and fibrous and fatty tissue displacement of the striated fibers. ${ }^{4}$ Clark et $a l^{5}$ also demonstrated lack of muscle fibers, endomysial and perimysial fibrosis, and, in addition, identified accumulation of an abnormal extracellular material includes collagen type III and fibronectin by immunohistochemistry.

Congenital ptosis is generally sporadic, but rarely hereditary. Several genes include PTOS1, PTOS2, and ZFH-4 have been identified in autosomal-dominant forms of isolated congenital ptosis. ${ }^{6-8}$

Acquired aponeurotic ptosis is caused by stretching or dehiscence of the levator aponeurosis or disinsertion of the aponeurosis from its normal position. Involutional weakening is a common cause of this type of ptosis. Aponeurotic ptosis can also occur after trauma, ocular surgery, and eyelid edema. ${ }^{1,2}$

Specimens of eyelids from patients with acquired blepharoptosis showed disinsertion of the levator aponeurosis and normal Müller's muscle. ${ }^{9}$ Collin et al ${ }^{10}$ found no evidence of
'Department of Ophthalmology, Ankara University School of Medicine, Ankara, Turkey

${ }^{2}$ Department of Pathology, Ankara Atatürk Education and Research Hospital, Ankara, Turkey

${ }^{3}$ Department of Pathology, Hacettepe University, Schoo of Medicine, Ankara, Turkey

Correspondence: E Şahlı, Department of Ophthalmology, Ankara University School of Medicine, Dikimevi, Ankara, Turkey Tel: +0 903125956231 ; Fax: +0 903123638082 . E-mail: esracansizoglu@ gmail.com

This study has been presented as a poster at the 29th ESOPRS Meeting, Cernobbio, Lake Como, Italy, September 2011.

Received: 22 May 2012 Accepted in revised form: 4 March 2013 Published online: 19 April 2013 
Müller's muscle disinsertion in patients with congenital and aponeurotic blepharoptosis. However, they demonstrated that Müller's muscle became thinner and longer with increasing age.

The structure and thickness of levator aponeurosis were evaluated by ultrasound biomicroscopy in previous studies. The levator aponeurosis was imaged, disinserted, or attenuated in most of the eyelids with aponeurotic blepharoptosis. ${ }^{11,12}$ In addition, relation between the thickness of the levator aponeurosis and the palpebral fissure height was shown in patients with aponeurotic ptosis. ${ }^{12}$

Apoptosis is an intracellular process in which cells activate a genetically controlled cell suicide program in response to a specific stimulus. Several stimuli, including cytokines, growth factors, and enzymes, can activate the genetic program of cell death. These stimuli triggered apoptosis via activating a series of morphological and biochemical changes in the cell. These changes include nuclear membrane breakdown, cytoskeletal reorganization, plasma-membrane blebbing, loss of cell adhesion, and shrinking of nuclei with condensation of the chromatin. ${ }^{13}$ Apoptosis occurs in numerous ocular tissues, including the retina, lens and cornea during embryogenesis, and in congenital and acquired ocular pathologies, such as glaucoma, age-related macular degeneration, and diabetic retinopathy. ${ }^{14-16}$

Over the years, a number of methods have been developed to detect apoptosis. There are several techniques, such as Annexin V, Caspase 3, and TUNEL assay. As Annexin V detects externalization of phosphatidylserine on the cytoplasmic membrane in the early apoptotic process, Caspase 3 activates the modulators of the apoptotic pathway. TUNEL assay is a method for examining apoptosis via detection of fragmented DNA, which occurs close to the final step in the apoptotic process. ${ }^{17,18}$ In this study, apoptosis detection was performed using Apop Tag Plus Peroxidase In Situ Apoptosis Detection Kit, which uses the TUNEL method. The Apop Tag kit labels apoptotic cells by modifying DNA fragments, utilizing terminal deoxynucleotidyl transferase to discover apoptotic cells by specific staining. This test kit has been used before to detect apoptosis in uterine carcinosarcoma, prostate carcinoma, gastric carcinoma, colorectal carcinoma, and pancreas carcinoma in the literature. ${ }^{19-23}$

The underlying cause of aponeurotic ptosis is still controversial. Although some of the patients with aponeurotic ptosis have predisposant factors, such as trauma, ocular surgery, or recurrent eyelid edema, the etiology is unknown in other patients. In addition, these factors precipitate ptosis only in susceptible individuals. The cause of dehiscence or disinsertion of levator aponeurosis is not certain in patients who had no predisposant causes.

The purpose of this study is to evaluate whether the apoptotic process has a function in the pathogenesis of aponeurotic blepharoptosis. The congenital myogenic ptosis group was accepted as the control group. To our knowledge, this is the first study to evaluate the relation between apoptosis and blepharoptosis.

\section{Materials and methods}

Forty-three consecutive patients, who underwent levator resection surgery for ptosis correction in the Department of Ophthalmology, Ankara University School of Medicine, Ankara, Turkey, between May 2007 and November 2009, were included in the study. All patients were questioned about the onset and progression of ptosis, and history of any possible causes, such as trauma, ocular surgery, eyelid edema, or systemic diseases. Written informed consent was obtained from all patients and controls. The study was conducted in accordance with the principles of the Declaration of Helsinki.

Patients who had neurogenic disease that originated from the oculomotor nerve and sympathetic nerve, and those who had Marcus Gunn jaw winking syndrome, were excluded from the study. Patients who had acquired myogenic diseases, such as Myasthenia Gravis, muscular dystrophy, and mechanic reason or history of trauma, were not included in the study. Only those patients who had congenital myogenic ptosis and acquired aponeurotic ptosis were included in the study.

Ophthalmic evaluation was performed as follows: visual acuity, anterior and posterior segment evaluation, palpebral fissure height in primary gaze, levator palpebrae superioris function, lid position on downgaze, skin crease, orbicularis function, Bell's phenomenon, and Marcus Gunn phenomenon. Functions of extraocular muscles and pupillary reactions were also evaluated. Ptotic eyes were defined as those with palpebral fissure heights less than $9 \mathrm{~mm}$, or $2 \mathrm{~mm}$ or more difference between two eyelids. None of the patients had a lower lid retraction.

All patients underwent levator surgery for treatment of ptosis. Levator resection surgery was performed via exposure of levator aponeurosis through the anterior approach in the two groups. The distal part of the levator aponeurosis and muscle was fixed and saved in 95\% ethyl alcohol. Apoptotic cells were determined using Apop Tag Plus Peroxidase In Situ Apoptosis Detection Kit (Chemicon International, Temecula, CA, USA). Tissue sections were mounted on coated slides, deparaffinized in a graded series of ethanols, rehydrated, and pretreated with proteinase $\mathrm{K}$ for $15 \mathrm{~min}$ at room temperature. 
Deparaffinized sections were treated with methanol containing $3 \% \mathrm{H}_{2} \mathrm{O}_{2}$ for $5 \mathrm{~min}$, for endogenous peroxidase blockage. After applying $75 \mu \mathrm{l}$ of equilibration buffer for $30 \mathrm{~min}$ at room temperature, $55 \mu \mathrm{l} / 5 \mathrm{~cm}^{2}$ of working strength TdT enzyme was pipetted onto sections and incubated in a humidified chamber at $37^{\circ} \mathrm{C}$ for $1 \mathrm{~h}$. After applying working strength stop/wash buffer for $10 \mathrm{~min}, 65 \mu \mathrm{l} / 5 \mathrm{~cm}^{2}$ anti-digoxigenin peroxidase conjugate were pipetted onto each slide, and the slides were incubated in a humidified chamber for $30 \mathrm{~min}$ at room temperature. After washing in PBS, peroxidase was visualized by diaminobenzidine tetrahydrochloride containing $3 \% \mathrm{H}_{2} \mathrm{O}_{2}$. Nuclei were stained with hematoxylin.

Immunohistochemical staining was evaluated and scored simultaneously by two pathologists using doubleheaded microscope, without knowledge of clinical data. Presence of brown-stained cells and morphological changes indicative of apoptosis, such as chromatin condensation and nuclear fragmentation, were read positive (Figure 1). Apoptotic cells were counted in 10 consecutive fields, which had the highest integrity of apoptotic cells. The apoptotic index was calculated by dividing the total number of apoptotic bodies by the total number of cells, and multiplying by 100 .

Statistical analysis was carried out using SPSS 10 Software (SPSS Inc., Chicago, IL, USA). Mann-Whitney's $U$-test and $\chi^{2}$-test were used for analysis. A value of $P<0.05$ was required for statistical significance.

\section{Results}

Forty-five eyelids of 43 patients with blepharoptosis (16 female, 27 males) were included in the study. Twenty-six of them were congenital myogenic ptosis and 19 of them were aponeurotic ptosis. The mean age was 12.5 years (ranging from 2 to 58 ) in the congenital ptosis group, and 49.3 years (ranging from 35 to 71 ) in the aponeurotic ptosis group.

The mean levator palpebrae superioris function was $8.4 \mathrm{~mm}$ (range 5-10 $\mathrm{mm}$ ) in the congenital ptosis group and $12.1 \mathrm{~mm}$ (range $10-17 \mathrm{~mm}$ ) in the aponeurotic ptosis group. The mean height of the vertical palpebral fissure in patients with congenital ptosis and aponeurotic ptosis were $6.5 \mathrm{~mm}$ (range 5-9 $\mathrm{mm}$ ) and $6.1 \mathrm{~mm}(3-9 \mathrm{~mm}$ ), respectively. The mean height of the lid crease of 19 patients with congenital ptosis was $5.2 \mathrm{~mm}$ (range 2-9 $\mathrm{mm}$ ), and the lid crease was not present in 5 patients in the congenital ptosis group. The mean height of the lid crease was $7.5 \mathrm{~mm}$ (range $3-11 \mathrm{~mm}$ ) in 16 patients with aponeurotic ptosis, and the lid crease was absent in 3 patients in the aponeurotic ptosis group.

The apoptotic index was 27.3 (range from 16 to 39) in the congenital ptosis group and 29.8 (range from 18 to 41 ) in the aponeurotic apoptosis group. No statistically significant difference was found between the congenital and aponeurotic ptosis groups in a mean apoptotic index, obtained from the levator muscle aponeurosis $(P=0.308$ and $P=297$, respectively). Apoptotic index was not correlated with age, levator palpebrae superioris function, palpebral fissure height, and lid crease height in two groups $(P \geq 0.05)$.

\section{Discussion}

Congenital myogenic blepharoptosis is an idiopathic, persistent ptosis, noticed shortly after birth. The amount of levator palpebrae superioris function usually correlates with the degree of ptosis, and poor or absent levator palpebrae superioris function is reflected in the absence of the eyelid crease. Understanding of the underlying cause and histology of this condition is difficult. It is controversial whether the condition should be classified as a dystrophy or a dysgenesis. ${ }^{3}$ Hornblass et $\mathrm{al}^{24}$ concluded that the myofibers showed characteristics of a progressive degenerative process and that congenital ptosis should be classified as a muscular dystrophy. Sutula ${ }^{4}$ commented that a dystrophy usually implies initial normal development followed by degeneration, whereas his impression was of an abnormal development, and therefore the condition had features of a dysgenesis. Lemagne et $a l^{25}$ concluded that ptosis resulted from abnormal development of the anterior portion of the muscle, where the fibers were replaced by fibrous tissue. The posterior limit of this fibrosis would determine the degree of ptosis and levator palpebrae superioris function. In considering the embryogenesis, they suggested that there could be a failure of differentiation and fusion of the anterior portion of the superior orbital mesoderm complex. ${ }^{25}$

In acquired aponeurotic ptosis, the ptosis is usually severe because of an aponeurotic deficiency, although the levator palpebrae superioris function is still intact, as assessed by electromyography. There is a local or general disinsertion or dehiscence of the aponeurosis from the tarsal plate. ${ }^{26}$ In aponeurotic ptosis due to advanced age, the long-term effects of gravity and aging cause stretching of the levator muscle and its aponeurosis. The muscle becomes thin, resulting in a loss of muscle tone and the inability to hold the upper lid in the proper position above the eye. Chronic inflammation or intraocular surgery can also incite weakness of the levator aponeurosis from the anterior surface of the tarsal plate. Patients who wear hard contact lenses or have a history of severe eye infection, cataract surgery, or blunt trauma to the eye may have an increased risk for aponeurotic ptosis. ${ }^{27}$ In some patients, aponeurosis defect can occur at a younger age and without a 

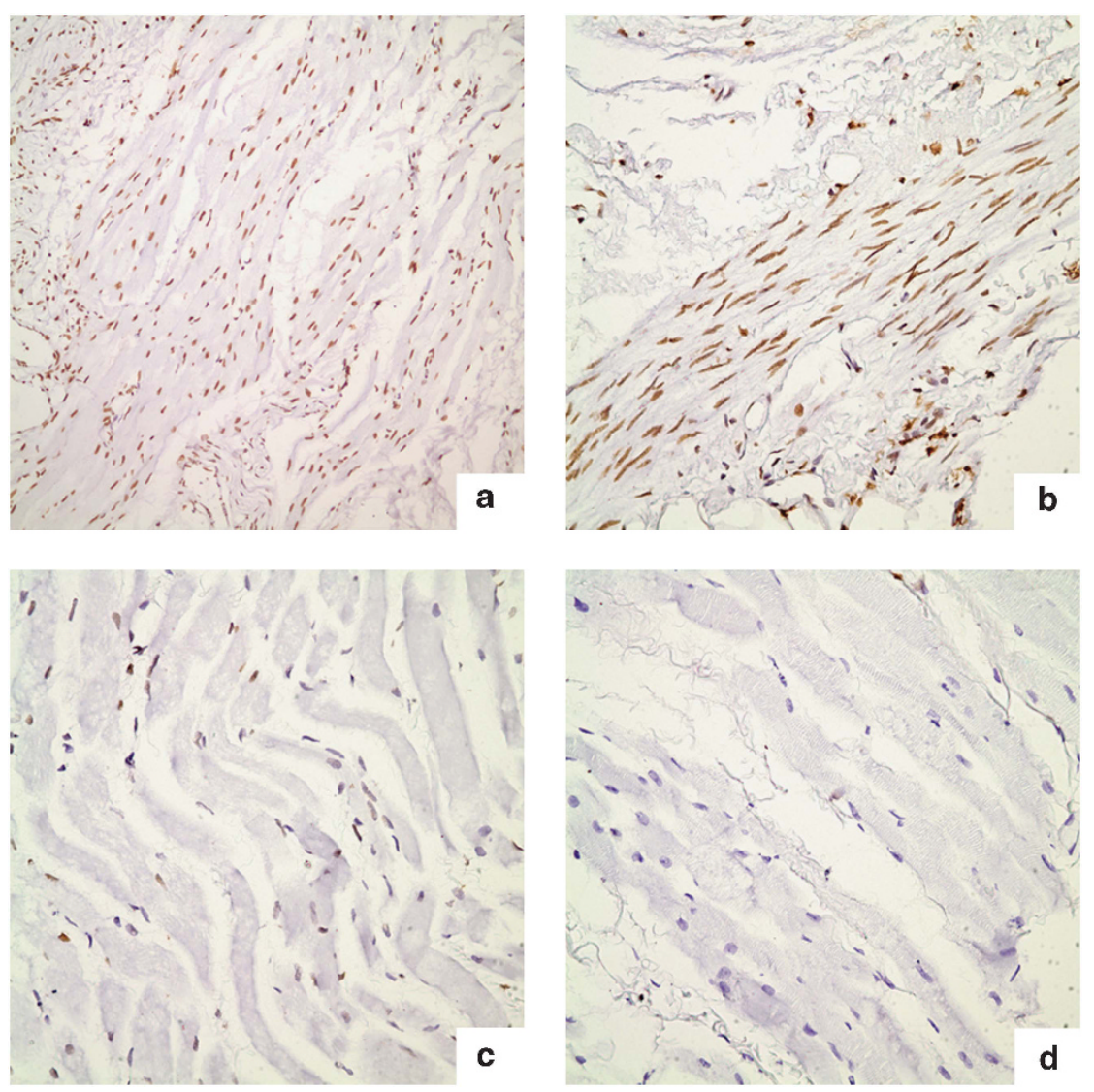

Figure 1 Immunohistochemical staining by Apop tag. (a, b) Increased apoptotic count: (a) $\times 20$ (from the congenital ptosis group) and (b) $\times 40$ (from the aponeurotic ptosis group). (c, d) Decreased apoptotic count: (c) $\times 40$ (from the congenital ptosis group) and (d) $\times 40$ (from the aponeurotic ptosis group).

precipitating factor. Another mechanism can have a function in developing aponeurosis damage in these patients.

Apoptosis is a form of programmed cell death that can be induced in susceptible cells by a wide variety of normal physiological stimuli as well as by deleterious environmental conditions and cytotoxic agents. ${ }^{28}$ Although apoptosis is present in all tissues it proceeds rapidly, and cells undergoing apoptosis disappear within hours. Physiologically occurring apoptosis is hardly detected histopathologically. The significance of apoptosis is increasingly recognized both in physiological regulation and in pathological situations. Apoptosis is a gene-directed process and can be seen as a response to external and internal stimuli. It has been demonstrated that apoptosis has a role in a variety of eye diseases. The effect in the pathogenesis of glaucoma, cataract, retinitis pigmentosa, age-related macular degeneration, retinoblastoma, and conjunctival and eyelid tumors, has been proved. ${ }^{16,29}$

Twenty-four patients with congenital myogenic ptosis and 19 with aponeurotic ptosis were included in the study. The mean age of the two groups were 12.5 and 49.3 years, respectively. We found no statistically significant difference between congenital and aponeurotic ptosis groups in a mean apoptotic index, obtained from the levator muscle aponeurosis. Because of the etiology, there was a large difference in mean age between the groups. The result of the study might change, if the sample size was larger or the groups were age-matched groups.

The two pathologists together evaluated the specimens by using a double-headed microscope. Hence, the two pathologists totally agree with each other for apoptosis in the specimens. Specimens were evaluated for apoptotic index and apoptotic morphological changes by the pathologists, without any knowledge of the patient groups and etiology. Therefore, evidence of any other differences in histological feature between groups was not considered.

In this study we evaluated the role of apoptosis in acquired aponeurotic blepharoptosis. Patients with congenital myogenic ptosis constituted our control group. Although we demonstrated apoptotic cells in the levator muscle and aponeurosis, we could not find statistically significant difference between two subtypes of blepharoptosis in the amount of apoptosis. Therefore, 
given the results of our study, the apoptotic process seems not to be responsible for the development of acquired aponeurotic ptosis. But there may be potential confounders, such as sample size and sensitivity of the apoptosis detection method, that could affect the result of the study. Further studies will be needed to demonstrate the role of apoptosis in aponeurotic apoptosis.

\section{Summary}

\section{What was known before}

- Local or general disinsertion or dehiscence of the levator aponeurosis cause aponeurotic ptosis.

\section{What this study adds}

- The apoptotic process is not responsible for the development of acquired aponeurotic ptosis.

\section{Conflict of interest}

The authors declare no conflict of interest.

\section{References}

1 Clauser L, Tieghi R, Galie M. Palpebral ptosis: clinical classification, differential diagnosis, and surgical guidelines: an overview. J Craniofac Surg 2006; 17: 246-254.

2 American Academy of Ophthalmology. Periocular malpositions and involutional changes. In: Basic and Clinical Science Course (BCSC) Section 7: Orbit, Eyelids, and Lacrimal System. American Academy of Ophthalmology: San Francisco, CA, 2007; 201-255.

3 Baldwin HC, Manners RM. Congenital blepharoptosis: a literature review of the histology of levator palpebrae superioris muscle. Ophtal Plast Reconstr Surg 2002; 18 301-307.

4 Sutula FC. Histological changes in congenital and acquired blepharoptosis. Eye 1988; 2: 179-184.

5 Clark BJ, Kemp EG, Behan WMH, Lee WR. Abnormal extracellular material in the levator palpebrae superioris complex in congenital ptosis. Arch Ophthalmol 1995; 113: 1414-1419.

6 Engle EC, Castro AE, Macy ME, Knoll JH, Beggs AH. A gene for isolated congenital ptosis maps to a 3-cM region within 1p32-p34.1. Am J Hum Genet 1997; 60: 1150-1157.

7 McMullan TF, Collins AR, Tyers AG, Robinson DO. A novel $\mathrm{X}$-linked dominant condition: X-linked congenital isolated ptosis. Am J Hum Genet 2000; 66: 1455-1460.

8 McMullan TW, Crolla JA, Gregory SG, Carter NP, Cooper RA, Howell GR et al. A candidate gene for congenital bilateral isolated ptosis identified by molecular analysis of a de novo balanced translocation. Hum Genet 2002; 110: 244-250.

9 Dortzbach RK, Sutula FC. Involutional blepharoptosis: A histopathological study. Arch Ophthalmol 1980; 98: 2045-2049.

10 Collin JRO, Beard C, Wood I. Experimental and clinical data on the insertion of the levator palpebrae superioris muscle. Am J Ophthalmol 1978; 85: 792-801.
11 Hosal BM, Pavlin CJ, Hurwitz JJ. Clinical use of ultrasound biomicroscopy in involutional blepharoptosis. Orbit 1994; 13(4): 167-171.

12 Hosal BM, Ayer NG, Zilelioğlu G, Elhan AH. Ultrasound biomicroscopy of the levator aponeurosis in congenital and aponeurotic blepharoptosis. Ophthal Plast Reconstr Surg 2004; 20(4): 308-311.

13 Bosman FT, Visser BC, van Oeveren J. Apoptosis: pathophysiology of programmed cell death. Path Res Pract 1996; 192: 676-683.

14 Tezel TH, Del Priore LV. Reattachment to a substrate prevents apoptosis of human retinal pigment epithelium. Graefes. Arch Clin Exp Ophthalmol 1997; 235: 41-47.

15 Tezel G, Wax MB. Inhibition of caspase activity in retinal cell apoptosis induced by various stimuli in vitro. Invest Ophthalmol Vis Sci 1999; 40: 2660-2667.

16 Nickells RW, Zack DJ. Apoptosis in ocular disease: a molecular overview. Ophthalmic Genetics 1996; 17: 145-165.

17 Willingham MC. Cytochemical methods for the detection of apoptosis. J Histochem Cytochem 1999; 47: 1101-1109.

18 Sgonc R, Gruber J. Apoptosis detection: an overview. Exp Gerontol 1998; 33: 525-530.

19 Jinfeng M, Kimura W, Sakurai F, Moriya T, Takeshita A, Hirai I. Histopathological study of intraductal papillary mucinous tumor of the pancreas: special reference to the roles of Survivin and p53 in tumorigenesis of IPMT. Int J Gastrointest Cancer 2002; 32: 73-81.

20 Kawasaki H, Toyoda M, Shinohara H, Okuda J, Watanabe I, Yamamoto T et al. Expression of surviving correlates with apoptosis, proliferation, and angiogenesis during human colorectal tumorigenesis. Cancer 2001; 91: 2026-2032.

21 Yoshida Y, Kurokawa T, Fukuno N, Nishikawa Y, Kamitani N, Kotsuji F. Markers of apoptosis and angiogenesis indicate that carcinomatous components play an important role in the malignant behavior of uterine carcinosarcoma. Hum Pathol 2000; 31: 1448-1454.

22 Szende B, Romics I, Torda I, Bely M, Szegedi Z, Lovasz S. Apoptosis, mitosis, p53, bcl(2), Ki-67 and clinical outcome in prostate carcinoma treated by androgen ablation. Urol Int 1999; 63: 115-119.

23 Ohtani M, Isozaki H, Fujii K, Nomura E, Niki M, Mabuchi H et al. Impact of the expression of cyclin-dependent kinase inhibitor p27Kip1 and apoptosis in tumor cells on the overall survival of patients with non-early stage gastric carcinoma. Cancer 1999; 85: 1711-1718.

24 Hornblass A, Adachi M, Wolintz A, Smith B. Clinical and ultrastructural correlation in congenital and acquired ptosis. Ophthal Surg 1976; 7: 69-76.

25 Lemagne JM, Colonval S, Moens B, Brucher JM. Anatomical modification of the levator muscle of the eyelid in congenital ptosis. Bull Soc Belge Ophthalmol 1992; 243: 23-27.

26 Baroody M, Holds JB, Vick VL. Advances in the diagnosis and treatment of ptosis. Curr Opin Ophthalmol 2005; 16: 351-355.

27 Sakol PJ, Mannor G, Massaro BM. Congenital and acquired blepharoptosis. Curr Opin Ophthalmol 1999; 10: 335-339.

28 Maulik N, Yoshida T, Das DK. Oxidative stres developed during the reperfusion of ischemic myocardium induces apoptosis. Free Radic Biol Med 1998; 24: 869-875.

29 Reszec J, Sulkowska M, Kanczuga-Koda L, Janica J, Skawronska M, Pepinski W et al. Evaluation of apoptosis markers in conjunctival and eyelid benign and malignant tumors. Ann NY Acad Sci 2003; 1010: 748-751. 